\title{
Growth Response of Chrysanthemum to Various Container Medium Moisture Tension Levels
}

\author{
P.A. Kiehl', J.H. Lieth', and D.W. BurgeF \\ Department of Environmental Horticulture, University of California, Davis, CA 95616-8587 \\ Additional index words. Dendranthema $\times$ grandiflorum, drip irrigation, moisture content, tensiometer
}

\begin{abstract}
A computer-controlled drip irrigation system was used to implement three types of moisture regimes in the potting medium of container-grown chrysanthemum [Dendranthema $\times$ grandiflorum (Ramat.) Kitamura] plants: "constant" moisture tension treatments were maintained by setting low- and high-tension set-points to the same value; "variable" tension treatments were imposed by setting the low- and high-tension set-points to 2 and 7 kPa, respectively, "timed" irrigation consisted of irrigating once per day for a fixed (excessive) duration that resulted in fluctuations in tension ranging from $O$ to $10 \mathrm{kPa}$. Constant moisture tension conditions in the range of 0.8 to $16 \mathrm{kPa}$ showed decreasing fresh and dry weight patterns with increasing tension, decreasing average moisture content, decreasing amounts of applied irrigation solution, and, consequently, with decreasing amounts of nutrients applied. Plants grown under conditions where the moisture content fluctuated appreciably (variable and timed) tended to be larger than those grown within the narrow tension ranges (constant); for the latter, optimal plant growth occurred at the lowest tension (0.8 kpa) and highest average moisture content $(71 \%)$. For fluctuating conditions, the control (with the widest fluctuations) had the highest dry weight growth. The variable tension treatments, while resulting in average moisture tensions of 4.4 to $4.9 \mathrm{kpa}$, resulted in plant growth similar to plants grown at constant low tension (0.8 to $1.6 \mathrm{kPa})$, rather than those grown at tensions between 4 and $5 \mathrm{kPa}$.
\end{abstract}

Experimentation on the effect of root-zone moisture content on plant growth requires the ability to accurately measure and control moisture content of the root-zone substrate. Models relating moisture tension to moisture content (van Genuchten, 1980) allow tensiometers to be used to maintain relatively uniform levels of moisture content. Tensiometers have been used in many field crop studies to determine the effects of soil moisture on various aspects "of growth, such as plant height, fresh and dry weight gain, and crop yield (Stanhill, 1956; Taylor, 1951). While most of these studies were carried out under field conditions or in containers using field soils, there have only been a few studies involving ornamental plants growing in media of high porosity that consist of mixes of sand, peatmoss, mulches, and various other components typically used in greenhouse production (de Boodt et al., 1974; Hanan and Langhans, 1964b; Röber and Hafez, 1981). Studies involving manipulation of moisture tension have shown declining trends in plant growth with increasing, sustained moisture tensions.

While the existence of optimal soil moisture content ranges for plant growth has been demonstrated for some ornamental crops (Johnson et al., 1981; Lieth and Burger, 1989; Röber and Hafez, 1981; Spomer and Langhans, 1975; Wikle et al., 1961), in one study on chrysanthemum (Karlovich and Fonteno, 1986), no differences in growth under various soil moisture regimes were observed.

Imposition of specific moisture tension levels has been fairly difficult in the past. Hanan and Langhans (1964a) used various depths of the root zone to impose a range of moisture tensions for snapdragon growing in benches containing various rooting

Received for publication 11 Jan. 1991. Accepted for publication 17 Oct. 1991 This work was funded. in part, by the California Assn. of Nurserymen. The cost of publishing this" paper was defrayed in part by the payment of page charges. Under postal regulations, this paper therefore must be hereby marked advertisement solely to indicate this fact.

'Currently Instructor, Dept. of Ornamental Horticulture, Foothill College, 12345 El Monte Road, Los Altos Hills, CA 94022-4599.

${ }^{2}$ Associate Professor and Extension Specialist, to whom reprint requests should be addressed.

${ }^{3}$ Associate Professor. media. They found that moisture contents between $24 \%$ and $34 \%$ were optimal (Hanan and Langhans, 1964b). For their media, this range corresponded to a moisture tension range of $\approx 2$ to $5 \mathrm{kPa}$ (Hanan and Langhans, 1964a). Frenz (1974) described a method for automated irrigation using mercury manometers as tension-controlled switches to irrigate at various moisture tensions. de Boodt et al. (1974) and Röber and Hafez (1981) also investigated the effect of moisture tension on ornamental plant growth using this type of system. They were unable to define precise optimal moisture tension values but indicated that the optimum falls between 2 and $5 \mathrm{kPa}$.

Lieth and Burger (1989) developed a computer-controlled drip irrigation system that used tensiometers equipped with pressure transducers to irrigate chrysanthemum plants growing in containers. They maintained constant levels of moisture content by maintaining approximately constant moisture tensions of 1.4, $3.5,5.5$, and $9.6 \mathrm{kPa}$. They observed decreases in plant weight with increasing tension (decreasing water content) and found that this effect was primarily due to reductions in leaf and stem weights. Flower weight was less affected. At the same time, reductions in the amounts of water applied ranged from $76 \%$ to $92 \%$ over their control treatment (daily watering for 5 rein). This ability to control vegetative growth and save water is particularly useful in the production of potted chrysanthemums. The objectives of this study were to use this irrigation system to 1) investigate the response of potted chrysanthemums to constant levels of potting medium moisture tension and 2) investigate the relationship between final total plant size and tension set-point.

\section{Materials and Methods}

The computerized drip irrigation system (Lieth and Burger, 1989) consisted of tensiometers equipped with pressure transducers, an analog-to-digital converter, a portable microcompu-

\footnotetext{
Abbreviations: EC, electrical conductivity; FD, flower diameter; FDW, flower dry weight; FFW, flower fresh weight; FN, number of flowers per pot; HGT, plant height; LDW, leaf dry weight; LFW, leaf fresh weight; SDW, stem dry weight; SFW, stem fresh weight; TDW, total dry weight, TFW, total fresh weight.
} 
ter, and solenoid-activated drip irrigation equipment. The tensiometers consisted of 16-mm (o.d.) acrylic tubing $\approx 75$ to $85 \mathrm{~mm}$ long with a porous ceramic cup (\#652X07-B1M3; Soil Moisture Equipment, Santa Barbara, Calif.) at one end and a rubber sleeve stopper at the other end (Burger and Paul, 1987). Pressure transducers were attached to' the tensiometer through a hole in this stopper. The data logger/controller consisted of an anolog-to-digital converter (OWL87; Electronically Monitored Ecosystems, Berkeley, Calif.) connected to a lap-top computer (Model 102; Tandy, Fort Worth, Texas). Differential amplifiers were used to amplify and convert the transducer signal into the $\mathrm{O}$ to $1.28 \mathrm{~V}$ DC range. The five output channels of the OWL87 "were used to control solid-state" relays that activated the solenoid valves.

A BASIC program running on the computer continuously monitored the container medium moisture tension corresponding to each tensiometer. Every $5 \mathrm{~min}$ these tension values were compared with preset threshold tension set-points. When a treatment tension was above its "high" set-point, the corresponding output channel was activated, opening the appropriate solenoid valve to irrigate plants in that treatment. The valve was closed when the tension dropped below the "low" set-point or when some maximum duration (10 see) had elapsed. With this equipment three types of treatments were imposed: 1) "constant tension" treatments were imposed by setting the high and low thresholds to the same value, 2) "variable tension" treatments were imposed by having substantially different high and low thresholds (e.g., the $7 / 2-\mathrm{kPa}$ treatment began irrigating at $7 \mathrm{kPa}$ and stopped irrigating when the tension reached $2 \mathrm{kPa}$ ), and 3) control or' 'timed" treatments were imposed by letting the computer irrigate for fixed durations. The irrigation solution was always half-strength Hoagland's solution \#2 (Hoagland and Arnon, 1950).

The irrigation water delivery system consisted of solenoid valves (Toro 264-06-03), black polyethylene irrigation tubing, and heavy-wall Chapin weighted drip lines (813 mm long, 0.91 $\mathrm{mm}$ id., $3.25 \mathrm{~mm}$ o.d.). One emitter was placed in the center of each pot. Before experimentation, the flow rate from each emitter was determined, and the uniformity was adjusted by replacing out-of-range emitters until delivery rates of all emitters were within $4 \%$ of each other.

With this equipment, potted chrysanthemum crops were grown during three separate experimental periods (Table 1). Rooted cuttings of 'Bright Golden Anne' chrysanthemums (Yoder Brothers, Barberton, Ohio) were planted in 150-mm-diameter (1.4 liter). plastic pots containing UC mix [1 peatmoss :1 sand : 1 redwood sawdust (by volume)]. Each pot contained five cuttings that were watered daily until the various treatments were started. All plants were grown under long-day conditions by interrupting the dark period using 100-W incandescent lights from 10:00 PM to 2:00 AM for several days after planting. After that, flower bud initiation and development were promoted by

Table 1. Dates of events during the three experiments.

\begin{tabular}{lccr}
\hline & \multicolumn{3}{c}{ Experiment } \\
\cline { 2 - 4 } Event & $1(1988)$ & $2(1989)$ & $3(1989)$ \\
\hline Planting & 10 Sept. & 16 Feb. & 5 Oct. \\
Start of experiment & 15 Sept. & 28 Feb. & 17 Oct. \\
Vegetative period (light) & $13-16$ Sept. & 16 Feb. -2 Mar. & $5-19$ Oct. \\
Flower initiation (dark) & 16 Sept. & 9 Mar. & 19 Oct. \\
Pinching & 24 Sept. & 2 Mar. & 19 Oct. \\
Harvest & 27 Nov. & 9 May & 20 Dec. \\
\hline
\end{tabular}

using black cloth from 4:30 PM to 8:30 AM to impose longnight conditions. Plants were pinched to five to seven leaves and grown as standards. Dates for the start of the phases of the experiments were recorded (Table 1). In each of the three experiments, treatments were arranged in a factorial design on the greenhouse bench.

Each experiment consisted of five treatments, of which one was a control treatment where the plants were watered once or twice daily for 3 or $5 \mathrm{~min}$ (application rate: 1.9 to $3.1 \mathrm{ml} \cdot \mathrm{sec}^{-1}$ ). The date, time of day, moisture tension of each treatment, air temperature just above canopy level, and the total length of time each valve was on during the previous $30 \mathrm{~min}$ were recorded by the computer every $30 \mathrm{~min}$. One pot per treatment contained a tensiometer that was placed in the center of the pot with the porous cup $\approx 6 \mathrm{~cm}$ from the bottom. The tension measured at the porous cup in this representative pot was used to determine irrigation requirements for all other pots in that treatment. Average tensions were calculated for each treatment. The percent moisture content was estimated for each 30-min tension average using a moisture release curve (van Genuchten, 1980) fitted for UC mix (Fig. 1). These numbers were averaged over the entire experimental period to arrive at an overall average moisture content value for each treatment.

Constant tension (Expt. 1). This experiment consisted of the control treatment (one irrigation per day, $3 \mathrm{~min} \cdot$ day $^{-1}$ up to 19 Oct. 1988, $5 \mathrm{~min} \cdot$ day-1 thereafter) and four constant tensions: $2,4,8$, or $16 \mathrm{kPa}$. Water was collected from one emitter in each treatment (except the control) during six periods of the experiment. The volume of water collected was measured every few days and discarded. Delivery rate of the emitters was calculated by dividing the volume of water collected by the duration each valve was open (recorded by the computer) for each period.

Constant vs. variable tension (Expt. 2). Experiment 2 consisted of the control treatment ( $5 \mathrm{~min} /$ irrigation, once per day up to 11 Apr. 1989, twice per day thereafter), three constant tension treatments: $1,3,5 \mathrm{kPa}$, and a variable tension treatment where the solenoid valve was turned on when the tension reached $7 \mathrm{kPa}$ and turned off when the tension dropped below $2 \mathrm{kPa}$ $(7 / 20-\mathrm{kPa})$. Irrigation water was collected from one emitter in each treatment. Total amounts of water applied in each treatment were determined periodically by weighing this accumulated water.

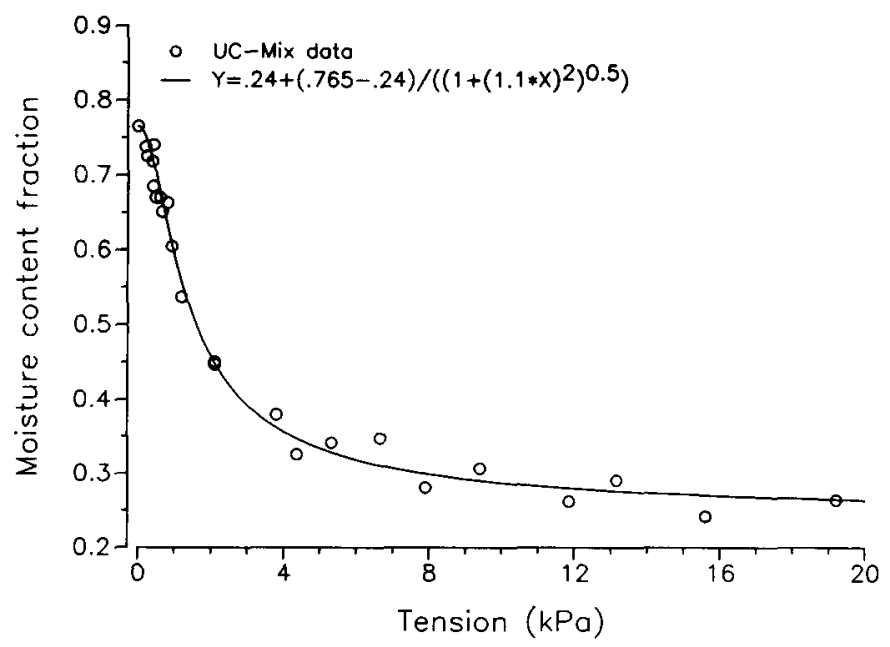

Fig. 1. Moisture release curve (van Genuchten, 1980) calibrated for UC mix. 
Constant vs. variable tension vs. periodically changed constant tension (Expt. 3). This test consisted of the control treatment (one irrigation per day for 5 rein), two constant tensions treatments $(0.8$ and $1.6-\mathrm{kPa})$, a variable $7 / 2-\mathrm{kPa}$ treatment (as in Expt. 2), and a constant tension treatment where the set-point was adjusted weekly to match the average tension of the 7/2$\mathrm{kPa}$ treatment during the previous week (designated Avg-7/2 $\mathrm{kPa}$ ). The total volume of water applied was determined as in Expt. 2.

For the pots in Expt. 3, electrical conductivity (EC) and $\mathrm{pH}$ of the container medium were measured at the end of the experiment by making a saturated paste from a sample of the potting medium. Four pots per treatment were sampled, and $\mathrm{pH}$ was measured directly on the paste using a $\mathrm{pH}$ meter (Model 125; Corning Science Products, Medfield, Mass.). The paste was then filtered, and the EC of the filtrate was measured using a Solu-Bridge Soil' Tester (Model RD-15; Industrial Instruments, Cedar Grove, N.J.).

At harvest of each experiment, plant height (HGT) was measured from the level of the medium to the top of the flower canopy for each pot. Individual flower diameters (FD) and the number of flowers per pot (FN) were recorded. Flowers, leaves, and stems were separated to determine fresh weights (FFW, LFW, SFW) and dry weights (FDW, LDW, SDW). These were used to calculate total top fresh and dry weights (TFW, TDW). Analyses of variance were carried out using the general linear models procedure (PROC GLM) of the Statistical Analysis System (SAS Institute, 1988). Since no one variable was suitable as a continuous independent variable for regression analyses, multiple-comparison tests (Scheffe's test, $P=0.05$ ) were used to determine whether treatment means were significantly different.

\section{Results}

The patterns of moisture tension during the course of the experiments were similar to those observed by Lieth and Burger (1989). The constant tension treatments resulted in fluctuations of tension where the amplitude increased with moisture tension set-point. This variation was not surprising since it is generally recognized that implementation of perfectly constant moisture conditions is impossible (Krizek, 1985).

Experiment 1. For all fresh and dry weight variables of Expt. 1 (Table 2), the highest mean values were observed for the control; values for the 2 - and $4-\mathrm{kPa}$ treatments were significantly lower than those for the control, but not different from each other. Plant part fresh and dry weight means for the 8- and $16-\mathrm{kPa}$ treatments were significantly lower than the other three treatments, but did not differ significantly from each other. Means for HGT and FN were not significantly different among the five treatments. The average FD of the control treatment was significantly higher than the $8-$ and $16-\mathrm{kPa}$ treatments.

The plants in the control treatment received the most water. The 2- and 4-kPa treatment plants received roughly equal amounts, but almost half as much as the control. The plants in the 8- and $16-\mathrm{kPa}$ treatments received the lowest amounts of water. No drainage from any pots, except the control, was observed; therefore, all of the water applied to the tension-controlled plants was either transpired by the plant or evaporated from the soil.

Experiment 2. Except for FFW, FDW, and TDW, the fresh and dry weight means for Expt. 2 (Table 3) were highest for the control plants, followed by the plants from the 1 - and $7 / 2$ $\mathrm{kPa}$ treatments, followed by those of the 3- and $5-\mathrm{kPa}$ treatments. Fresh and dry weight means for the $1-$ and $7 / 2-\mathrm{kPa}$ treat-
Table 2. Average tensions, average moisture contents, volume of water applied, and plant growth variables for the five treatments in Expt. 1. Means in rows followed by the same letter are not significantly different at $P=0.05$ using Scheffe's multiple-comparison test.

\begin{tabular}{|c|c|c|c|c|c|c|c|c|c|c|}
\hline \multirow[b]{2}{*}{ Characteristic } & \multicolumn{10}{|c|}{ Treatment } \\
\hline & \multicolumn{2}{|c|}{$2 \mathrm{kPa}$} & \multicolumn{2}{|c|}{$4 \mathrm{kPa}$} & \multicolumn{2}{|c|}{$8 \mathrm{kPa}$} & \multicolumn{2}{|c|}{$16 \mathrm{kPa}$} & \multicolumn{2}{|c|}{ Control } \\
\hline $\begin{array}{l}\text { Avg tension } \\
(\mathrm{kPa})\end{array}$ & 2.0 & & 3.9 & & 6.4 & & 9.8 & & 4.1 & \\
\hline $\begin{array}{l}\text { Avg moisture } \\
\text { content }(\%)\end{array}$ & 55.0 & & 37.8 & & 30.6 & & 27.5 & & 51.1 & \\
\hline $\begin{array}{l}\text { Water applied } \\
\text { (liters) }\end{array}$ & 17.43 & & 17.36 & & 16.67 & & 15.35 & & 34.40 & \\
\hline SFW (g) & 118 & b & 121 & $b$ & 95.5 & $\mathrm{c}$ & 96.0 & $\mathrm{c}$ & 187 & a \\
\hline LFW (g) & 143 & b & 145 & b & 115 & c & 119 & c & 213 & $\mathrm{a}$ \\
\hline FFW (g) & 216 & b & 216 & $\mathrm{~b}$ & 175 & c & 172 & $\mathrm{c}$ & 293 & a \\
\hline TFW (g) & 477 & b & 483 & b & 385 & $\mathrm{c}$ & 387 & $\mathrm{c}$ & 693 & a \\
\hline SDW (g) & 24.0 & b & 24.4 & $\mathrm{~b}$ & 20.3 & c & 21.2 & $\mathrm{c}$ & 28.9 & a \\
\hline LDW (g) & 15.4 & b & 15.4 & $\mathrm{~b}$ & 12.6 & c & 13.2 & $\mathrm{c}$ & 19.4 & a \\
\hline FDW (g) & 19.9 & $\mathrm{~b}$ & 20.3 & $\mathrm{~b}$ & 16.9 & $\mathrm{c}$ & 16.9 & c & 23.9 & $\mathbf{a}$ \\
\hline TDW (g) & 59.3 & b & 60.1 & $\mathrm{~b}$ & 49.8 & $\mathrm{c}$ & 51.2 & c & 72.2 & $\mathbf{a}$ \\
\hline HGT (mm) & 539 & a & 553 & $\mathbf{a}$ & 525 & $\mathbf{a}$ & 538 & $\mathbf{a}$ & 554 & $\mathbf{a}$ \\
\hline FN & 21.0 & a & 21.0 & a & 20.6 & $\mathrm{a}$ & 19.7 & a & 21.2 & $\mathbf{a}$ \\
\hline $\mathrm{FD}(\mathrm{mm})$ & 97 & $\mathrm{ab}$ & 99 & $a b$ & 97 & $\mathrm{~b}$ & 95 & $\mathrm{~b}$ & 106 & $\mathbf{a}$ \\
\hline
\end{tabular}

Table 3. Average tensions, average moisture contents, volume of water applied, and plant growth variables for the five treatments in Expt. 2. Means in rows followed by the same letter are not significantly different at $P=0.05$ using Scheffe's multiple-comparison test.

\begin{tabular}{|c|c|c|c|c|c|c|c|c|c|c|}
\hline \multirow[b]{2}{*}{ Characteristic } & \multicolumn{10}{|c|}{ Treatment } \\
\hline & \multicolumn{2}{|c|}{$1 \mathrm{kPa}$} & \multicolumn{2}{|c|}{$3 \mathrm{kPa}$} & \multicolumn{2}{|c|}{$5 \mathrm{kPa}$} & \multicolumn{2}{|c|}{$7 / 2 \mathrm{kPa}$} & \multicolumn{2}{|c|}{ Control } \\
\hline $\begin{array}{l}\text { Avg tension } \\
(\mathrm{kPa})\end{array}$ & 1.2 & & 3.1 & & 4.2 & & 4.4 & & 8.0 & \\
\hline $\begin{array}{l}\text { Avg moisture } \\
\text { content }(\%)\end{array}$ & 66.6 & & 44.0 & & 37.5 & & 39.0 & & 49.5 & \\
\hline $\begin{array}{l}\text { Water applied } \\
\text { (liters) }\end{array}$ & 21.19 & & 20.43 & & 18.35 & & 22.21 & & 54.50 & \\
\hline SFW (g) & 182 & $\mathrm{~b}$ & 151 & $\mathrm{c}$ & 152 & $\mathrm{c}$ & 177 & b & 263 & a \\
\hline LFW (g) & 224 & $\mathrm{~b}$ & 184 & $\mathrm{c}$ & 178 & c & 213 & b & 340 & a \\
\hline FFW (g) & 261 & $a b$ & 228 & $\mathrm{~b}$ & 227 & $\mathrm{~b}$ & 249 & $a b$ & 281 & a \\
\hline TFW (g) & 667 & $\mathrm{~b}$ & 564 & $\mathrm{c}$ & 557 & $c$ & 640 & $\mathrm{~b}$ & 884 & a \\
\hline SDW (g) & 43.3 & $b$ & 37.2 & $\mathrm{c}$ & 34.5 & c & 43.1 & $\mathrm{~b}$ & 47.2 & $\mathrm{a}$ \\
\hline LDW (g) & 25.0 & $\mathrm{~b}$ & 21.6 & c & 20.1 & $\mathrm{c}$ & 24.9 & $\mathrm{~b}$ & 30.5 & $\mathrm{a}$ \\
\hline FDW (g) & 30.1 & $\mathrm{a}$ & 27.0 & $a b$ & 24.8 & $\mathrm{~b}$ & 29.5 & $a b$ & 29.5 & $a b$ \\
\hline TDW (g) & 98.4 & $\mathrm{a}$ & 85.8 & $b$ & 79.3 & $\mathrm{~b}$ & 97.6 & $\mathrm{a}$ & 107 & $\mathrm{a}$ \\
\hline $\mathrm{HGT}(\mathrm{mm})$ & 678 & $a b$ & 681 & $a b$ & 661 & bc & 703 & a & 629 & c \\
\hline FN & 17.9 & a & 15.9 & $\mathrm{a}$ & 16.1 & a & 16.9 & a & 17.6 & a \\
\hline $\mathrm{FD}(\mathrm{mm})$ & 109 & a & 108 & $\mathrm{a}$ & 105 & $\mathrm{a}$ & 107 & a & 112 & $\mathrm{a}$ \\
\hline
\end{tabular}

ments were not significantly different; those of the 3- and 5$\mathrm{kPa}$ treatments were also not significantly different. The mean TDW values for the control and $1-$ and $7 / 2-\mathrm{kPa}$ treatments were significantly higher than for the 3 - and 5-kPa treatments. The only significant differences in FDW means were between the 1 - and 5-kPa treatments. FFW means of the 3- and 5-kPa treatments were significantly different from the control but not from the other two treatments. The plants of the control treatment were the shortest; those of the $7 / 2-\mathrm{kPa}$ treatment were the tallest. There were no significant differences among treatment means for FN and FD.

All plants irrigated based on tension received $<50 \%$ of the amount of water delivered to the control plants. Plants in the $7 / 2-\mathrm{kPa}$ treatment used more water than the $1-\mathrm{kPa}$ treatment, 
followed by the 3- and 5-kPa treatments (Table 3). Some water leached from several pots of each treatment after 6 May. The total volume of water leached was $<400 \mathrm{ml} /$ pot.

Experiment 3. Plants grown under the control treatment had the highest dry weight variable means in Expt. 3 (Table 4). No significant differences were found between means of the 0.8 and 1.6-kPa treatments or between those of the 1.6- and 7/2$\mathrm{kPa}$ treatments. While SFW and LFW from the Avg-7/2-kPa and $7 / 2-\mathrm{kPa}$ treatments differed significantly, SDW and LDW did not. No significant differences in FFW or FDW, FN, and FD were observed among the treatments.

Plants in the $0.8-\mathrm{kPa}$ treatment received more water than those 'in the $7 / 2-\mathrm{kPa}$ treatment, followed by those in the $1.6-\mathrm{kPa}$ and the Avg-7/2-kPa (Table 4). Although the Avg-7/2-kPa treatment was adjusted periodically to match the average tension calculated for the $7 / 2-\mathrm{kPa}$ treatment, the latter used 0.66 liters/pot more water for the 10-week crop period than the Avg-712-kPa treatment. Only 0.11 liters more water were supplied to each pot of the $7 / 2-\mathrm{kPa}$ than to each pot of the $1.6-\mathrm{kPa}$ treatment.

Mean EC values ranged from 2.1 to $3.4 \mathrm{mS} \cdot \mathrm{cm}^{-1}$, but the differences among means were not statistically significant. Treatment means for $\mathrm{pH}$ ranged from 5.2 to 6.3 , with the means for the control samples significantly lower than those of the other treatments.

\section{Discussion}

The moisture release curve for UC mix (Fig. 1) shows that this medium, in a 1.4-liter container, holds $\approx 75 \%$ of its volume in water at container capacity (near $0 \mathrm{kPa}$ ). Between 0 and 2 $\mathrm{kPa}$, there is a rapid decline in moisture content with increasing tension. Above $2 \mathrm{kPa}$, the tension increases rapidly with small amounts of water being removed. Thus, at high tensions, addition or removal of small amounts of water result in large changes in tension, while the same change in moisture content at lower tensions results in small changes in tension. Of the total

Table 4. Average tensions, average moisture contents, volume of water applied, and plant growth variables for the five treatments in Expt. 3. Means in rows followed by the same letter are not significantly different at $P=0.05$ using Scheffe's multiple comparison test.

\begin{tabular}{|c|c|c|c|c|c|c|c|c|c|c|}
\hline \multirow[b]{2}{*}{ Characteristic } & \multicolumn{10}{|c|}{ Treatment } \\
\hline & \multicolumn{2}{|c|}{$0.8 \mathrm{kPa}$} & \multicolumn{2}{|c|}{$1.6 \mathrm{kPa}$} & \multicolumn{2}{|c|}{ Avg-7/2 kPa } & \multicolumn{2}{|c|}{$7 / 2 \mathrm{kPa}$} & \multicolumn{2}{|c|}{ Control } \\
\hline $\begin{array}{l}\text { Avg tension } \\
(\mathrm{kPa})\end{array}$ & 0.8 & & 1.6 & & 4.7 & & 4.9 & & 2.8 & \\
\hline $\begin{array}{l}\text { Avg moisture } \\
\text { content }(\%)\end{array}$ & 70.7 & & 61.4 & & 35.2 & & 34.5 & & 49.8 & \\
\hline $\begin{array}{l}\text { Water applied } \\
\text { (liters) }\end{array}$ & 14.31 & & 11.95 & & 11.40 & & 12.06 & & $42^{z}$ & \\
\hline SFW (g) & 147 & b & 142 & $b$ & 114 & c & 146 & b & 196 & $\mathbf{a}$ \\
\hline LFW (g) & 192 & b & 183 & bc & 151 & d & 174 & c & 249 & $\mathbf{a}$ \\
\hline FFW (g) & 141 & a & 141 & a & 129 & a & 149 & a & 156 & $\mathbf{a}$ \\
\hline TFW (g) & 480 & b & 466 & $b$ & 394 & c & 470 & b & 601 & $\mathbf{a}$ \\
\hline SDW (g) & 24.6 & $a b$ & 23.0 & $\mathrm{bc}$ & 20.0 & d & 21.8 & $\mathrm{~cd}$ & 26.3 & $3 \mathrm{a}$ \\
\hline LDW (g) & 18.9 & $\mathrm{~b}$ & 17.9 & bc & 15.6 & d & 16.8 & $c d$ & 21.3 & $3 \mathrm{a}$ \\
\hline FDW (g) & 15.4 & $\mathrm{a}$ & 14.7 & $\mathbf{a}$ & 14.0 & $\mathbf{a}$ & 15.2 & $\mathrm{a}$ & 16.0 & \\
\hline TDW (g) & 58.9 & $a b$ & 55.6 & $\mathrm{bc}$ & 49.5 & c & 54.0 & $\mathrm{bc}$ & 63.6 & \\
\hline HGT (mm) & 548 & a & 530 & $\mathrm{a}$ & 529 & a & 544 & a & 554 & a \\
\hline FN & 16.2 & $\mathbf{a}$ & 16.1 & $\mathrm{a}$ & 16.2 & a & 16.1 & a & 16.1 & \\
\hline $\mathrm{FD}(\mathrm{mm})$ & 87.6 & a & 87.9 & $\mathrm{a}$ & 87.0 & $\mathbf{a}$ & 94.1 & $\mathbf{a}$ & 91.6 & $6 a$ \\
\hline
\end{tabular}

${ }^{x}$ Estimated by assuming emitter rate of $2 \mathrm{ml} \cdot \mathrm{sec}^{-1}$, application duration of $5 \mathrm{~min} \cdot \mathrm{day}^{-1}$, and experimental period of 70 days. amount of water in the $\operatorname{mix}, \approx 25 \%$ is not readily available to the plant. Thus, the high tensions imposed during Expt. 1 resulted in impositions of moisture contents close to the level where water is unavailable to the plant. This situation may explain the reduced plant sizes observed during Expt. 1. Although no wilting was observed for the plants in the $16-\mathrm{kPa}$ treatment, the data suggest that these plants may have been water-stressed. For the constant tension treatments, the trend is for lower TDW and TFW with increasing tension. This reduction, however, is not simply a correlation between average moisture tension or water content and plant growth. For example, while lower average moisture tensions (and higher moisture contents) were maintained in the 2-kPa treatment (Expt. 1) than in the control, the resulting plants were smaller. However, TFW tended to increase with the total amount of irrigation solution applied (Fig. 2) and, therefore, with total amount of fertilizer applied. Thus, it is possible that the observed decline in the weight variables with increasing tension may be due, in part, to the total amount of fertilizer applied.

The measurements from the three experiments cannot be compared directly since seasonal variations in light and temperature probably resulted in differences in accumulated biomass during the three experiments. However, changes in the relationship between the tension-based treatments and the control can be compared across the experiments by considering the ratio of treatment TDW $\left(\mathrm{TDW}_{\mathrm{i}}\right.$ ) to TDW of the control (TDW control). This ratio was always less than 1.0 in this study since the control plants were the largest in each of the experiments. Plant growth relative to the control declined with increasing average tension and increased with average moisture content (Fig. 3). The relative plant sizes in the variable tension treatments $(7 / 2 \mathrm{kPa})$ were similar to those of plants grown at significantly lower constant tensions $(0.8$ to $2 \mathrm{kPa})$. This result suggests that, for equal average tension regimes, the wider ranges of tensions are more optimal for growth than narrow ranges. For the control, where the tensions ranged from 0 to $>10 \mathrm{kPa}$, the ratio is equal to 1 . Thus, if this observed pattern is not due to variations in nutrient availability, then it may be concluded that constant (narrow range) tension treatments are suboptimal. The $\mathrm{TFW}_{\mathrm{i}}$ : $\mathrm{TFW}_{\text {control }}$ ratio showed the same phenomenon.

Differences in tension had a much smaller effect on the growth and development of flowers (FFW, FDW, FN, and FD) than on leaves and stems, except in the highest tension treatments (8.0 and $16.0 \mathrm{kpa}$ ), a result consistent with observations by Lieth and Burger (1989) for single-stem chrysanthemum. It does, however, contra-

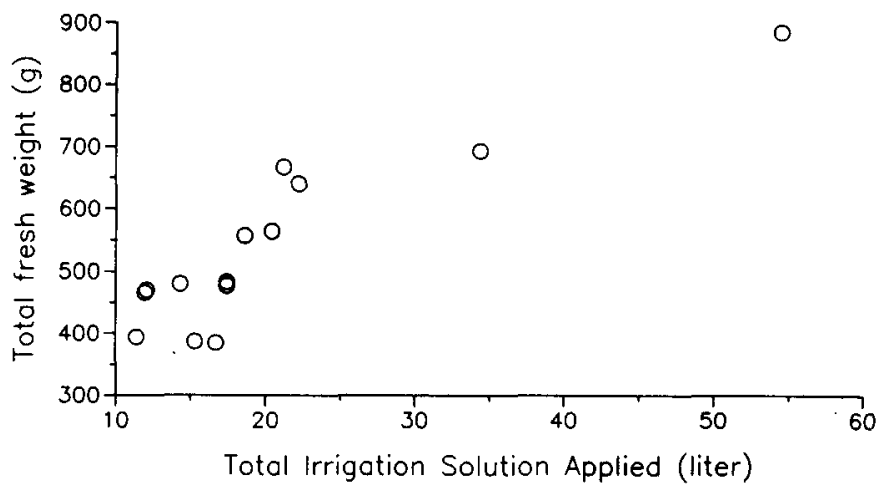

Fig. 2. Average TFW for each treatment of the three experiments as a function of total amounts of irrigation solution during the entire crop cycle. 


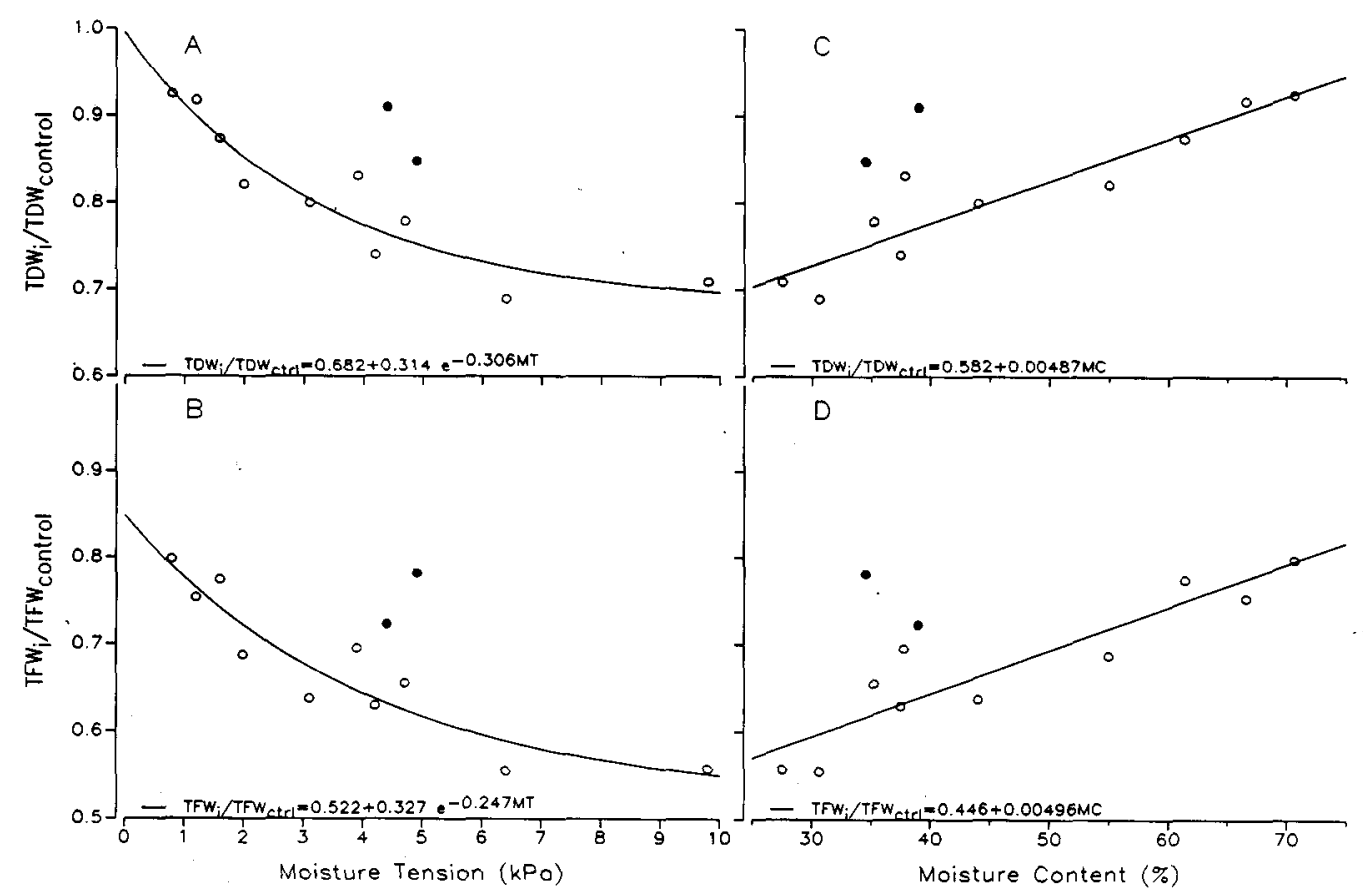

Fig. 3. Dry (A, C) and fresh (B, D) weight fraction of the control for each treatment, $i$, of the experiments vs. moisture tension $(\mathbf{A}, \mathbf{B})$ and content $(\mathbf{C}, \mathbf{D})$. Open and closed circles are the constant and variable tension treatments, respectively.

dict the results of Röber and Hafez (1981), who reported a decline in FFW with increasing tension from 3 to $12 \mathrm{kPa}$.

While Lieth and Burger (1989) and Röber and Hafez (1981) observed a significant decline in plant height with increasing moisture tension, this trend was not found to be significant in any of the three experiments of this study. In Expts. 1 and 3, the mean heights of the control were larger, but the differences were not significantly different. In the case of control plants in Expt. 2, their mean height was significantly lower than that of the plants of the other treatments, except for the driest treatment $(5 \mathrm{kPa})$. These height reductions were probably due to a period of $\approx 15$ hot, sunny days when control plants frequently experienced tensions ranging from 10 to $90 \mathrm{kPa}$, which resulted in wilting. (Shortly thereafter, whitewash was sprayed on the exterior of the greenhouse glazing to reduce the light intensity inside the greenhouse. Control pots were watered twice daily for the remainder of the experiment). The impact of these high tensions on plant height suggests that height control through controlled high moisture tensions may be a possibility for potted chrysanthemum but that tensions significantly higher than the highest one we tested $(16 \mathrm{kPa})$ would have to be used.

With the exception of the control plants, most of the plants experienced no leaching during the entire crop period. Thus, we were surprised that no salt accumulated in the medium. Measurements made in Expt. 3 indicated there was no significant elevation of EC or $\mathrm{pH}$ values during the 10-week crop period. Values fell into the acceptable range $\left(2.0-4.0 \mathrm{mS} \cdot \mathrm{cm}^{-1}\right)$ for container-grown ornamental (Nelson, 1985). The irrigation solution, used in these experiments was made from deionized water and had an EC of $2.0 \mathrm{mS} \cdot \mathrm{cm}^{-1}$ and a $\mathrm{pH}$ of 5.5 . Using a high-quality water source such as this probably minimized the rate of salt accumulation. For situations where the water quality is not as high, some leaching may be required to ensure that EC levels do not exceed the acceptable range. It is also possible that under the conditions provided by our irrigation system, higher salt levels can be tolerated since their concentration is never allowed to escalate because the water content never drops below some critical level.

As suggested by Lieth and Burger (1989), the effects of increased moisture tension on chrysanthemum are to reduce the overall plant size relative to standard irrigation practices. This effect is accomplished without proportional declines in flower sizes. Since compact size and full, showy flowering is the goal for potted chrysanthemum production, the feasibility for imposing high, controlled moisture tensions in a commercial production nursery should be explored.

Apart from the utility of the system used here for height control, this research showed that crops can be grown successfully by irrigation based on maintenance of low, but constant, soil moisture tensions. Tensions between 0.8 and $1.5 \mathrm{kPa}$ resulted in crops with TDW means that were not significantly different from the control. The variable tension treatments, which resulted in plants not significantly different from those of low, constant tension treatments, showed the greatest promise for suitability in commercial settings, since these wider ranges of tensions can be implemented by converting existing drip irrigation systems to tension-based control through the use of tensiometers. The reduction in leachate provides an added benefit by reducing the amount of waste-water runoff from nurseries. Reduced amounts of Ieachate would also mean that less water and fertilizer are applied, resulting in economic savings.

\section{Literature Cited}

Burger, D.W. and J.L. Paul. 1987. Soil moisture measurements in containers with solid-state, electronic tensiometers. HortScience 22:309-310.

de Boodt, M., O. Verdonck, and I. Cappaert. 1974. Determination and study of the water availability of substrates for ornamental plant growing. Acts Hort. 35:51-58.

Frenz, F.W. 1974. Experiences with an automated watering-system for pot-grown vegetables in greenhouses. Acts Hort. 35:71-73.

Hanan, J.H. and R. W. Langhans. 1964a. Control of moisture content in greenhouse soils. Agron. J. 56:191-194. 
Hanan, J.H. and R.W. Langhans. 1964b. Soil water content and the growth and flowering of snapdragons. Proc. Amer. Soc. Hort. Sci. 84:613-623.

Hoagland, D.R. and D.I. Arnon. 1950. The water culture method of growing plants without soil. California Agr. Expt. Sta. Circ. 347. College of Agriculture, Berkeley, Calif.

Johnson, C. R., D.L. Ingram, and J.E. Barrett. 1981. Effects of irrigation frequency on growth, transpiration, and acclimatization of Ficus benjamina L. HortScience 16:80-81.

Karlovich, P.T. and W.C. Fonteno. 1986. Effect of soil moisture tension and soil water content on the growth of chrysanthemum in three container media. J. Amer. Soc. Hort. Sci. 111 :191-195.

Krizek, D.T. 1985. Methods for inducing water stress in plants. HortScience 20:1028-1038.

Lieth, J.H. and D.W. Burger. 1989. Growth of chrysanthemum using an irrigation system controlled by soil moisture tension. J. Amer. Soc. Hort. Sci. 114:387-392.

Nelson, P.V. 1985. Greenhouse operation and management. 3rd ed. Prentice-Hall, Englewood Cliffs, N.J.
Rober, R. and M. Hafez. 1981. The influence of different water supply upon the growth of chrysanthemums. Acts Hort. 125:69-78.

SAS Institute. 1988. SAS/STAT user's guide, release 6.03 ed. SAS Institute, Cary, N.C.

Spomer, L.A. and R.W. Langhans. 1975. The growth of greenhouse bench Chrysanthemum x morifolium Ramat. at high soil water contents: Effects of water and aeration. Commun. in Soil Sci. \& Plant Anal. 6(5):545-553.

Stanhill, G. 1956. The effect of differences in soil-moisture status on plant growth: A review and analysis of soil moisture regime experiments. Soil Sci. 84:205-215.

Taylor, S. 1951. Use of mean soil moisture tension to evaluate the effect of soil moisture on crop yields. Soil Sci. 74:217-226.

van Genuchten, M.T. 1980. A closed-form equation for predicting the hydraulic conductivity of unsaturated soils. Soil Sci. Soc. Amer. J. 44:892-898.

Wikle, J. S., H. Davidson, and E. Erickson. 1961. Soil moisture studies with container-grown plants. Mich. Quart. Bul. 44(1):125128. 